\title{
Associations of Social Cohesion and Socioeconomic Status with Health Behaviours among Middle-Aged and Older Chinese People
}

\author{
Zeyun Feng ${ }^{1,2, * \mathbb{D}}$, Jane M. Cramm ${ }^{1}$ and Anna P. Nieboer ${ }^{1} \mathbb{D}$ \\ 1 Erasmus School of Health Policy \& Management, Erasmus University Rotterdam, \\ 3000 DR Rotterdam, The Netherlands; Cramm@eshpm.eur.nl (J.M.C.); nieboer@eshpm.eur.nl (A.P.N.) \\ 2 Shanghai Health Development Research Center (Shanghai Medical Information Center), \\ Shanghai 200031, China \\ * Correspondence: feng@eshpm.eur.nl
}

Citation: Feng, Z.; Cramm, J.M.; Nieboer, A.P. Associations of Social Cohesion and Socioeconomic Status with Health Behaviours among Middle-Aged and Older Chinese People. Int. J. Environ. Res. Public Health 2021, 18, 4894. https:// doi.org/10.3390/ijerph18094894

Academic Editor: Emily A. Schmied

Received: 24 March 2021

Accepted: 2 May 2021

Published: 4 May 2021

Publisher's Note: MDPI stays neutral with regard to jurisdictional claims in published maps and institutional affiliations.

Copyright: (C) 2021 by the authors. Licensee MDPI, Basel, Switzerland. This article is an open access article distributed under the terms and conditions of the Creative Commons Attribution (CC BY) license (https:// creativecommons.org/licenses/by/ $4.0 /)$.

\begin{abstract}
Background: An understanding of factors associated with health behaviours is critical for the design of appropriate health promotion programmes. Important influences of social cohesion, education, and income on people's health behaviours have been recognised in Western countries. However, little is known about these influences in the older Chinese population. Objective: To investigate associations of social cohesion and socioeconomic status (SES) with health behaviours among middle-aged and older adults in China. Methods: We used data from the World Health Organization's Study on Global AGEing and Adult Health. Logistic regression and multivariate linear regression were performed. Results: Participants who reported greater social cohesion were more likely to have adequate vegetable and fruit (VF) consumption, be socially active, and less likely to smoke daily, but were not physically more active; participants with lower education levels were less likely to have adequate VF consumption and be socially active, and more likely to smoke daily; higher incomes were associated with decreased odds of daily smoking, increased odds of adequate VF consumption, increased likelihood to be socially active, but also less likelihood to have sufficient physical activity (PA). Associations of social cohesion and SES with health behaviours (smoking, PA, and VF consumption) differed between men and women. Discussion: Our findings are an essential step toward a fuller understanding of the roles of social cohesion and SES in protecting healthy behaviours among older adults.
\end{abstract}

Keywords: social cohesion; socioeconomic status; physical activity; healthy diet; smoking; social participation; health behaviour

\section{Introduction}

China, the country with the largest ageing population on Earth [1], is facing multiple health challenges [2]. Health deteriorates as people age, with increasing disease risk. Healthy behaviours are expected to slow health deterioration by preventing people from becoming ill, as well as by preventing the worsening of chronic illness [3]. Given the importance of leading a healthy lifestyle among older people in China, investigation of the factors associated with health behaviours is critical, and can be particularly useful for the prioritization of limited resources and targeting of public health interventions in the country.

Socioeconomic status (SES), conceptualised as education and income, has been found to be associated with health behaviours [4,5]. Among Chinese adults, for example, lesseducated people report lower levels of vegetable and fruit (VF) consumption [6] and higher levels of smoking [7]. People with lower incomes also reported inadequate VF consumption [8]. Diverse mechanisms underlie the relationships between SES disparities and unhealthy behaviours [5]. One classic explanation, termed the "healthy lifestyle" mechanism, is that adults with higher educational levels tend to avoid unhealthy behaviours 
(e.g., smoking) and to engage in healthy behaviours (e.g., exercise) because education enables people to be more aware of the health outcomes of their behaviours and to develop stronger self-control [9]. Another explanation is that wealthier adults are able to afford the expenses of gym membership and other leisure time associated with physical activity (PA) [10]. In China, however, associations among income, PA, and smoking are complex; people in rural China with lower incomes reported higher levels of work-related PA than did those with higher incomes [11]. Another study showed that women with lower incomes reported higher levels of domestic PA compared with the higher-income group [12] Possible explanations are that poorer rural residents must work for longer periods to earn livings; women with lower incomes are more likely to be stay-at-home housewives and thus participate more in domestic chores. Additionally, the association between income and smoking is not straightforward. How can we explain the fact that more than half of highly educated doctors in some areas of China are smokers, despite their knowledge of the harmful effects of smoking [13]? This phenomenon indicates that education and income alone are not sufficient to explain people's health behaviours. Factors other than SES disparities must empower people to adopt certain health behaviours; research has suggested that social circumstances [5] and social environmental factors such as social cohesion [14] can greatly influence such behaviours.

Empirical studies have highlighted the significant influence of social cohesion on people's health behaviours in Western countries [15-19]. For example, higher levels of social cohesion are associated with higher physical activity (PA) levels among older adults [16-18]. Social cohesion can promote PA in many ways [19]. More cohesive societies may be more likely to organize local activities, including sports/PA, that provide more opportunities for residents to adopt and maintain healthy behaviours [20,21]. Social cohesion also may reinforce healthy norms [21]; for example, seeing neighbours jog every day might encourage others to participate in such activities when the perceived safety level (an element of social cohesion) is high [17].

This mechanism may also apply to the maintenance of a healthy diet. Collective efficacy, another aspect of social cohesion, is grounded in mutual trust and describes a community's ability to create change and exercise informal social control (e.g., promote healthy vegetable and fruit (VF) consumption through social norms) [22]. Several scholars have found that greater social cohesion is associated with higher VF intake among adults [23] and adolescents [24], and benefits nutrition among children [25]; little attention has been given to this association in older adults. In a study conducted with 5900 adults living in urban neighbourhoods in five European countries, higher levels of social cohesion were associated positively with fruit, but not vegetable, intake [26].

The relationship between social cohesion and smoking appears to be less straightforward, as studies evaluating it have yielded different conclusions; some researchers found that greater social cohesion was associated with lower levels of smoking [27-29], whereas Andrews and colleagues [30] found no such association.

Apart from traditional health behaviours, social participation has also been reported recently to be a crucial health behaviour in later adulthood [31]. Studies conducted in Western countries, such as Great Britain [22,32] and the United States [33], have revealed a clear association between social cohesion and social participation among older adults, although evidence on this subject remains scarce, and whether this association holds among older adults in China remains unknown.

Numerous attempts have been made to conceptualize social cohesion [34,35]. In general, the term refers to trust levels and the absence of social conflict, interrelated societal characteristics [36,37], but an internationally accepted definition remains lacking. For this study, we adopted Chan and colleagues' [38] (pp. 290) definition: "social cohesion is a state of affairs concerning both the vertical and the horizontal interactions among members of a society, as characterized by a set of attitudes and norms that include trust, a sense of belonging, and the willingness to participate and help, as well as their behavioural manifestations." Researchers have proposed several indicators for its measurement $[39,40]$, including trust 
among citizens $[17,18,21,39-42]$ and perceived safety [39], which are expected to influence health behaviours.

Despite China's rapid economic growth in recent decades, the income gap (reflected by the Gini coefficient) in the country is ranked even higher than that in the United States [43]. It peaked in 2008 and then began to decline in 2010 [43]. According to the Committee on Social Affairs, Health and Sustainable Development (Council of Europe), a substantial body of evidence has shown that income inequality is a major threat to social cohesion [44]. The drastic economic development that has occurred in the past few decades in China has likely affected social cohesion. Thus, the investigation of social cohesion in China during the period of 2008-2010 is of particular interest.

Research investigating associations between social cohesion, SES, and health behaviours among older people in China is very limited; only one study revealed an association between social cohesion and leisure-time physical activity (LTPA) among older adults in Shanghai [21]. No study to date has explicitly examined associations of social cohesion and SES with multiple health behaviours in a national sample of older Chinese people. Although the importance of SES has been well documented in developed nations [5], less evidence is available for developing countries such as China. To fill this gap, we investigated associations of social cohesion and SES with various health behaviours (smoking, physical activity, VF consumption, and social participation) among middle-aged and older adults in China using a large nationwide database. As previous studies have revealed gender differences in health behaviours such as smoking in China [45], we also conducted a gender-stratified analysis of these associations.

\section{Methods}

\subsection{Participants and Data}

Data from Chinese participants in wave 1 (2008-2010) of the World Health Organization's (WHO's) Study on Global AGEing and Adult Health (SAGE) were used for the current study, which is the most recent available data from China. This period is also of interest because income inequality in China peaked in 2008 and only began to decline in 2010 [43]. SAGE is a nationally representative study of individuals aged $\geq 50$ years in six low- and middle-income countries (China, Ghana, India, Mexico, the Russian Federation, and South Africa). In China, the wave 1 survey was conducted in between 2008 and 2010 in 8 provinces/municipalities [46]. A multistage, stratified cluster sampling approach was used to select participants [46]. Approximately half of the face-to-face interviews were computer-assisted (CAPI), and half were assisted by manual data recording [46]. The individual response rate was excellent (93\%) [46]. Further details of WHO SAGE sampling have been provided elsewhere [47]. The sample for this study comprised 13,367 participants.

\subsection{Measures}

\subsubsection{Independent Variables \\ Social Cohesion Scale}

Social cohesion was operationalized by using a mean scale based on respondents answers to five questions about trust and safety developed by WHO SAGE as a social cohesion indicator: neighbourly trust, trust in co-workers, trust in strangers, perceived safety while staying alone at home, and perceived safety while walking alone in streets after dark (details shown in Appendix A). The original questionnaire requires respondents to rate the levels of trust/safety on a five-point scale. In our analyses, all answers were inverse-coded for convenience of interpretation. Meaning, for trust items, each answer was based on a five-point scale, ranging from 1 , denoting "to a very small extent" (1), to 5 , "to a very great extent" (5); for safety items, answers ranged from "not safe at all" (1) to "completely safe" (5). At least three out of five items needed to be answered. Higher scores indicated higher levels of social cohesion. 


\section{SES}

Based on previous research $[5,48,49]$, education and income were used to measure SES in our analyses. Individuals' educational levels were recorded as lower (completed primary school or less: 0 ) and higher (completed secondary school or more: 1). Individuals incomes were estimated by the WHO SAGE research team. The Bayesian postestimation method was used to estimate raw income based on income indicators such as various dwelling characteristics (e.g., type of floor), a set of household ownership of durable goods (e.g., number of chairs), and access to services (improved water, sanitation, and cooking fuel) [50].

\section{Sociodemographic Characteristics}

The following sociodemographic variables were controlled in our analyses: age (years), gender ( 0 , male; 1 , female), marital status $(0$, single (never married, separated/divorced, or widowed); 1 , married (currently married or cohabiting)), and area of residence ( 0 , urban; 1 , rural).

\subsubsection{Dependent Variables}

PA

PA was assessed using a dichotomous variable based on self-reported questionnaire responses. Participants were asked to report their vigorous and moderate PA. Vigorous PA included work activities (e.g., chopping, farm work, and digging with a spade or shovel) and sports, leisure, and recreational activities (e.g., jogging, running, swimming, heavy lifting, fitness, gym attendance, and rapid cycling). Moderate PA included washing clothes by hand, gardening, house cleaning, stretching, dancing, and cycling at regular pace. Participants were asked to recall the level of activities and the time spent on them in a typical week. We used the WHO-recommended thresholds (for individuals aged $\geq 18$ years) to classify PA as sufficient ( $\geq 150 \mathrm{~min}$ /week moderate or $\geq 75 \mathrm{~min}$ /week vigorous PA: 1 ) and insufficient ( $<150 \mathrm{~min} /$ week moderate or $<75 \mathrm{~min} /$ week vigorous PA: 0 ) [51].

\section{VF Consumption}

VF consumption was used as an indicator of healthy eating. We followed the WHO guidelines [51] to distinguish adequate ( $\geq 2$ servings fruit and $\geq 3$ servings vegetables/day: 1 ) from inadequate ( $<2$ servings fruit and $<3$ servings vegetables/day: 0$)$ VF consumption.

\section{Smoking}

Smoking behaviour was assessed by asking whether participants smoked daily. This variable was dichotomised as 0 (not a daily smoker) and 1 (daily smoker).

\section{Social Participation Scale}

Social participation was measured using a mean scale for the 9-item questionnaire developed for the SAGE (Appendix B), with questions such as "How often in the last 12 months have you attended any public meeting in which there was discussion of local or school affairs?". Responses ranging from "never" (1) to "daily" (5) denote the frequency of respondents' involvement in their communities. Total social participation scores were calculated by summing the item scores.

\section{Statistical Analysis}

As descriptive statistics, means, and standard deviations (SDs) of continuous variables (e.g., age) and numbers and percentages of categorical variables (e.g., gender) were calculated. The strength of associations between social cohesion and health behaviours (categorical variables: PA, VF consumption, and smoking) was evaluated by estimating odds ratios (ORs) with $95 \%$ confidence intervals (CIs) using a logistic regression model. The association between social cohesion and social participation (a continuous variable) was evaluated by estimating B coefficients and standard errors (SE) using a multivariate linear regression model. Social cohesion and SES variables (income and education) were 
entered into the models simultaneously while adjusting for key individual background characteristics (age, gender, marital status, and area of residence). To produce genderspecific analyses, stratified analyses were performed, while adjusting for age, marital status, and areas of residence. To assess the severity of multicollinearity, we calculated the variance inflation factors (VIF) among independents variables. The VIF score of all covariates did not exceed the recommended value of 10 [52]; which suggested that there were no multicollinearity problems among independent variables included in our analyses. The significance level was set at $p<0.01$. All statistical analyses were conducted using IBM SPSS Statistics (version 27, IBM, Armonk, NY, USA).

\section{Results}

Table 1 shows the characteristics of the study participants. Of the 13,367 participants included, the mean age (SD) was 63.2 (9.44) years; $53.1 \%$ of participants were female, $83.1 \%$ were not single, $50.9 \%$ were from rural areas, and $61.7 \%$ had lower educational levels. Overall, the prevalence of smoking was $24.5 \%$, but a much higher proportion of smokers was male ( $48.9 \%$ vs. $3.0 \%$ female). The prevalence of inadequate VF consumption was $35.0 \%$, and $32.8 \%$ of participants reported insufficient PA. The mean social participation scale score was 1.7 (standard deviation, 0.4 ).

Table 1. Characteristics of the study population $(n=13,367)$.

\begin{tabular}{|c|c|c|c|}
\hline & $n$ & $\%$ & Mean (SD) \\
\hline \multicolumn{4}{|c|}{ Sociodemographic characteristics } \\
\hline Age (years) Range 50-99 & 13,367 & & $63.2(9.4)$ \\
\hline Gender (female) & 7093 & 53.1 & \\
\hline \multicolumn{4}{|l|}{ Marital status } \\
\hline \multicolumn{4}{|l|}{ Missing $10(0.1 \%)$} \\
\hline Non-single & 11,093 & 83.1 & \\
\hline Areas of residence (rural) & 6800 & 50.9 & \\
\hline \multicolumn{4}{|c|}{ SES and social cohesion variables } \\
\hline \multicolumn{4}{|l|}{ Educational level } \\
\hline \multicolumn{4}{|l|}{ Missing $72(0.5)$} \\
\hline Lower & 8202 & 61.7 & \\
\hline \multicolumn{4}{|l|}{ Income quintile } \\
\hline \multicolumn{4}{|l|}{ Missing $61(0.5)$} \\
\hline Q1 (lowest) & 2665 & 20.0 & \\
\hline Q2 & 2646 & 19.9 & \\
\hline Q3 & 2688 & 20.2 & \\
\hline$\widehat{Q} 4$ & 2724 & 20.5 & \\
\hline Q5 (highest) & 2583 & 19.4 & \\
\hline Social cohesion scale & & & \\
\hline Missing 429 (3.2) & 12,938 & & $3.4(0.5)$ \\
\hline \multicolumn{4}{|l|}{ Health behaviours } \\
\hline \multicolumn{4}{|l|}{ Daily smoker } \\
\hline \multicolumn{4}{|l|}{ Missing 443 (3.3) } \\
\hline Female & 209 & 3.0 & \\
\hline Male & 2954 & 48.9 & \\
\hline Total sample & 3163 & 24.5 & \\
\hline \multicolumn{4}{|l|}{ Inadequate VF consumption } \\
\hline \multicolumn{4}{|l|}{ Missing $1247(9.3)$} \\
\hline Female & 2013 & 28.4 & \\
\hline Male & 2223 & 39.0 & \\
\hline Total sample & 4236 & 35.0 & \\
\hline \multicolumn{4}{|l|}{ Insufficient PA } \\
\hline \multicolumn{4}{|l|}{ Missing 422 (3.2) } \\
\hline Female & 2284 & 33.2 & \\
\hline Male & 1960 & 32.3 & \\
\hline Total sample & 4244 & 32.8 & \\
\hline \multicolumn{4}{|l|}{ Social participation scale } \\
\hline \multicolumn{4}{|l|}{ Missing 419 (3.1) } \\
\hline Female & 6879 & & $1.7(0.4)$ \\
\hline Male & 6069 & & $1.7(0.4)$ \\
\hline Total & 12,948 & & $1.7(0.4)$ \\
\hline
\end{tabular}

SD, standard deviation; SES, socioeconomic status; VF, vegetables and fruit; PA, physical activity. No data on age, gender, residence were missing. Higher Social participation scores indicate greater social participation. 
Table 2 presents the results of the multivariate linear regression model and logistic regression models. In the analysis adjusted for age, gender, marital status, and residence, each unit of increase in the social cohesion score was associated with a $30 \%$ increase in the likelihood of adequate VF consumption ( $\mathrm{OR}=1.300 ; 95 \% \mathrm{CI}, 1.192-1.417 ; p<0.001)$; higher social cohesion was associated with lower odds of being a daily smoker $(\mathrm{OR}=0.839$; 95\% CI, 0.754-0.934; $p<0.01$ ); also, higher mean score of social cohesion was positively associated with higher levels of social participation $(\mathrm{B}=0.074, p<0.001)$. Regarding education, less-educated respondents were associated with lower odds of having adequate VF consumption ( $\mathrm{OR}=0.806 ; 95 \% \mathrm{CI}, 0.730-0.890 ; p<0.001)$, lower-educated respondents had a 31\% higher likelihood of being daily smokers $(\mathrm{OR}=1.314 ; 95 \% \mathrm{CI}, 1.166-1.480$; $p<0.001)$, and were less likely to be socially active $(B=-0.052, p<0.001)$ compared with people with higher levels of education. With respect to income, individuals with higher income were less likely to have sufficient PA (OR $=0.606 ; 95 \% \mathrm{CI}, 0.552-0.665 ; p<0.001)$, less likely to be daily smokers (OR $=0.790 ; 95 \% \mathrm{CI}, 0.699-0.891 ; p<0.001)$, more likely to have adequate $\mathrm{VF}$ consumption ( $\mathrm{OR}=2.650 ; 95 \% \mathrm{CI}, 2.396-2.932 ; p<0.001)$, and tend to be more socially active $(\mathrm{B}=0.101, p<0.001)$ compared with people with lower income.

Table 2. Relationships between social cohesion and socioeconomic status with four health behaviours.

\begin{tabular}{|c|c|c|c|c|c|}
\hline & \multirow{2}{*}{$\begin{array}{l}\text { Sufficient PA } \\
\text { OR }(95 \% \text { CI })\end{array}$} & \multirow{2}{*}{$\begin{array}{c}\text { Adequate VF Consumption } \\
\text { OR }(95 \% \mathrm{CI})\end{array}$} & \multirow{2}{*}{$\begin{array}{l}\text { Daily Smoker } \\
\text { OR }(95 \% \text { CI })\end{array}$} & \multicolumn{2}{|c|}{ Social Participation $\S$} \\
\hline & & & & B & SE \\
\hline \multicolumn{6}{|l|}{ Independent variables } \\
\hline Social cohesion & $\begin{array}{c}1.058 \\
(0.975-1.147)\end{array}$ & $\begin{array}{c}1.300 * * \\
(1.192-1.417)\end{array}$ & $\begin{array}{c}0.839 * \\
(0.754-0.934)\end{array}$ & 0.074 & $0.007^{* *}$ \\
\hline Education (low) & $\begin{array}{c}1.058 \\
(0.963-1.162)\end{array}$ & $\begin{array}{c}0.806^{* *} \\
(0.730-0.890)\end{array}$ & $\begin{array}{c}1.314^{* *} \\
(1.166-1.480)\end{array}$ & -0.052 & $0.008^{* *}$ \\
\hline Income & $\begin{array}{c}0.606^{* *} \\
(0.552-0.665)\end{array}$ & $\begin{array}{c}2.650 * * \\
(2.396-2.932)\end{array}$ & $\begin{array}{c}0.790 * * \\
(0.699-0.891)\end{array}$ & 0.101 & $0.008^{* *}$ \\
\hline \multicolumn{6}{|l|}{ Covariates } \\
\hline Age & $\begin{array}{c}0.960 * * \\
(0.956-0.964)\end{array}$ & $\begin{array}{c}1.000 \\
(0.995-1.005)\end{array}$ & $\begin{array}{c}0.959 * * \\
(0.953-0.964)\end{array}$ & -0.005 & $0.000^{* *}$ \\
\hline Gender (female) & $\begin{array}{c}0.937 \\
(0.867-1.013)\end{array}$ & $\begin{array}{c}1.510 * * \\
(1.390-1.640)\end{array}$ & $\begin{array}{c}0.027^{* *} \\
(0.023-0.032)\end{array}$ & -0.003 & 0.007 \\
\hline Residence (rural) & $\begin{array}{c}0.681 * * \\
(0.621-0.745)\end{array}$ & $\begin{array}{c}0.455^{* *} \\
(0.415-0.500)\end{array}$ & $\begin{array}{c}1.608^{* *} \\
(1.431-1.808)\end{array}$ & 0.122 & $0.008 * *$ \\
\hline Non-Single & $\begin{array}{c}1.078 \\
(0.968-1.200)\end{array}$ & $\begin{array}{c}1.330 * * \\
(1.188-1.489)\end{array}$ & $\begin{array}{c}0.787^{*} \\
(0.671-0.923)\end{array}$ & -0.003 & 0.010 \\
\hline Constant & $25.762 * *$ & 0.889 & $20.600 * *$ & & $1.679^{* *}$ \\
\hline $\mathrm{R} 2$ & $\begin{array}{c}0.047 \\
\text { (Nagelkerke) }\end{array}$ & $\begin{array}{c}0.153 \\
\text { (Nagelkerke) }\end{array}$ & $\begin{array}{c}0.445 \\
\text { (Nagelkerke) }\end{array}$ & & 0.062 \\
\hline$n$ & 12,822 & 12,005 & 12,797 & & 12,840 \\
\hline
\end{tabular}

${ }^{*} p<0.01,{ }^{* *} p<0.001$. SE, standard error; OR, odds ratio; CI, confidence interval. $\$$, continuous variable. PA, physical activity. Reference groups: male, urban residence, single, higher education. Higher Social participation scores indicate greater social participation.

Analyses controlled for key background characteristics (age, marital status, and area of residence) revealed significant gender differences in the associations of daily smoking and PA with social cohesion (Table A3, Appendix C). Higher levels of social cohesion were associated significantly with decreased odds of being a daily smoker among men $(\mathrm{OR}=0.805, p<0.001)$, but not among women. Such levels were associated significantly with sufficient PA only among men $(\mathrm{OR}=1.178, p<0.01)$. In addition, gender differences were found in the associations of education with adequate VF consumption and daily smoking (Table A3, Appendix C). Lower educational levels were associated significantly 
with reduced odds of adequate VF consumption among women $(\mathrm{OR}=0.723, p<0.001)$, but not men. Such levels were associated significantly with greater odds of being a daily smoker only among men $(\mathrm{OR}=1.320, p<0.001)$. In addition, higher incomes were associated significantly with reduced odds of being a daily smoker only among men $(\mathrm{OR}=0.807$, $p<0.01)$

\section{Discussion}

In general, this study revealed that older Chinese people with greater social cohesion are more likely to have adequate VF consumption and to be socially active, and less likely to be daily smokers, but were not physically more active. Participants with lower education levels were less likely to have adequate VF consumption and to participate in social activities, and were more likely to be daily smokers than those with more education. Higher incomes were associated with a reduced likelihood of being a daily smoker and increased likelihood of having adequate VF consumption and being socially active, but also a reduced likelihood of engaging in sufficient levels of PA. This study serves as a first step in the deepening of our knowledge of the crucial role of social cohesion for health behaviours among older adults in China.

\subsection{Associations of Social Cohesion with Health Behaviours}

Our finding that greater social cohesion decreased the odds of smoking, which is in agreement with previous research [27-29], supports the theory that social cohesion strengthens psychological resources (e.g., self-esteem and optimism) and helps to reduce smoking risk factors, such as distress [29]. Similarly, our finding that older people with greater social cohesion are more likely to be socially active is in accordance with findings from Western countries, such as the United States [33]. No comparable data for older adults in China were available. In highly collectivistic societies, people tend to limit their social activities, including only people in their inner circles; they tend to be comfortable participating in social activities with others only when they feel that they can trust them [53]. Our finding implies that the enhancement of older people's perceived safety and trust (vital elements of social cohesion) boosts their social participation. The lack of association between social cohesion and PA in this study is consistent with Legh-Jones and Moore's finding [54] that perceived generalized trust was not associated with PA among adults. However, other researchers have reported a positive association with LTPA [18,21,55]. This inconsistency may reflect the use of different PA measures among studies [19]. To be specific, we included multiple aspects of PA (e.g., gardening, walking, and household chores), whereas Lindström [55], Gao [21], and Van Dyck's [18] studies focused on the associations between social cohesion and LTPA specifically. Thus, social cohesion may be more relevant for leisure-time activities (e.g., going shopping, going to the movies, and dining at a restaurant) than for other types of PA (e.g., gardening and household chores). Finally, we observed a positive association between greater social cohesion and sufficient VF consumption among older adults. This finding is in line with the findings of a study conducted in Japan, which revealed that people living in more cohesive neighbourhoods more frequently had sufficient VF intakes [56]. Although empirical studies of VF receipt among older adults in China are lacking, older Chinese adults who cultivate VF are likely to more frequently share their products with neighbours they trust as an indicator of greater social cohesion. Previous findings on this topic are inconsistent. Barnidge and colleagues [57] found no significant association between social cohesion and VF consumption, and a multinational study conducted in Europe [26] revealed an association with fruit, but not vegetable, consumption. This discrepancy may be due to the examination of different study populations using different measures; we included middle-aged and older adults living throughout China, whereas Barnidge et al. [57] focused on older adults (mostly women) in rural settings in the United States and Mackenbach and colleagues [26] examined a general adult population from urban areas in Europe. Furthermore, we followed the WHO guidelines to distinguish adequate and inadequate VF consumption 
as one variable, Mackenbach and colleagues' [26] study measured fruit consumption and vegetable consumption separately as two variables. Additionally, as admitted by Barnidge and colleagues [57], their study potentially brought bias regarding the reporting of VF consumption because they used a single item to measure VF consumption. Our finding, however, is consistent with the expected presence of such an association, and expands our understanding of it in general older adult populations.

\subsection{Associations of SES with Health Behaviours}

Our finding that older Chinese adults with higher incomes were more likely to be physically inactive is in accordance with previous findings for Chinese adults [11]. Older adults with higher incomes are more likely to own and use (personal) vehicles [58], which decreases their daily engagement in physical activities such as walking and cycling. In addition, this group may be less likely than those with lower incomes to need to engage in physically demanding work, for example, by hiring workers to do household chores. Although we found that higher incomes decreased the risk of being a daily smoker among older Chinese adults, according to Zhang and colleagues' [59], national Chinese surveys have revealed no relationship between household income and smoking behaviour (among men). This inconsistency might be explained by an age difference among study samples; the national surveys were conducted with adults aged $\geq 18$ and $\geq 15$ years, respectively $[60,61]$. Although higher education levels have been associated with higher levels of exercise [62], we observed no such association in our overall sample. Age may also explain this discrepancy, as the previous study was conducted with individuals aged 15-69 [62]. In addition, only 31\% of participants in Gang et al.'s [62] study had lower educational levels (0-6 years of school), whereas $61.7 \%$ of our participants had completed primary school or less. Relationships between education levels and health behaviours need to be examined further.

\subsection{Gender Specific Findings}

This study revealed some gender differences related to smoking, PA, and VF consumption. Lesser social cohesion and lower educational levels and incomes were associated with daily smoking only among older Chinese men. These findings could be explained by the difference in smoking patterns between men and women $[63,64]$, and the corresponding small number of female smokers in our sample. Various surveys have revealed low prevalence rates for smoking among Chinese women [60]. For example, this rate was $2.4 \%$ in the 2010 Global Adult Tobacco Survey [65], likely because smoking is an accepted social norm for men, but not women, in China [66]. Greater social cohesion was associated with sufficient PA only among men in this study. In traditional Chinese culture, women are responsible for housework and are thus more likely than men to engage in domestic forms of PA (e.g., cooking and cleaning) [67]. Thus, social cohesion may have less influence on Chinese women's PA.

Lower educational levels were associated with inadequate VF consumption only among women in this study. A study conducted in Korea revealed an association between lower educational levels and lower VF intake, and specifically low consumption of yellow/orange vegetables in men and red fruit/vegetables in both men and women [68]. Due to differences in study samples and the measurement of VF consumption, comparison of our findings with those of Hong and colleagues [68] is difficult. Evidence regarding gender differences in the associations of social cohesion and SES with health behaviours in China is lacking. While this study provided a first insight into these gender differences, more studies are needed to gain an in-depth understanding of whether and how the mechanisms underlying older adults' social cohesion and health behaviours differ according to gender.

\subsection{Public Policy Implication}

The findings of this study provide valuable insight for policy development to promote healthy ageing among older adults in China. For instance, investment in the creation of safe 
neighbourhoods is expected to benefit older adults' health behaviours. Vest and Valdez [69] found that people who described their neighbourhoods as unsafe were almost three times more likely to be physically inactive than were people describing their neighbourhoods as extremely safe. Health policies should thus aim to create safe, walkable, and accessible neighbourhoods by increasing urban public space (e.g., community gardens and parks) to encourage older adults' outdoor (physical and social) activities and social interactions [70]. Furthermore, our findings highlight the importance of considering gender differences when designing health promotion strategies aiming to improve older Chinese adults' health behaviours.

\subsection{Study Strengths and Limitations}

This study contributes to the literature in several ways. First, China's unprecedented development has created a unique context for social scientists, as the rapid changes that have occurred have had profound impacts on the country's population. Specifically, scholars believe that economic growth can influence social cohesion [71]. This study is the first in which data from a large population-based sample were used to investigate the associations of social cohesion and SES with various health behaviours among older Chinese people. Second, we minimized bias by controlling for various potential confounders, such as sociodemographic factors, in our regression models.

Notwithstanding, several limitations of this study warrant mention. First, we could not assess causality or changes in social cohesion, SES, or health behaviours, due to the crosssectional study design. We encourage researchers to explore longitudinal relationships among these factors when wave 2 SAGE data become publicly available. In addition, bundling of health behaviours should be considered, as a previous study showed that people tend to gain weight when they quit smoking due to the consumption of more food/snacks as rewards for smoking withdrawal [72]. Second, we used VF consumption as an indicator of healthy diet due to limited data availability, although VF consumption alone cannot fully reflect individuals' dietary patterns. Thus, we urge researchers to collect more detailed dietary information according to the WHO guidelines, to augment our ability to assess these patterns. Third, the lack of global consensus on the definition of social cohesion-a well-known problem in this research field-makes the comparison of research findings difficult [41]. Fourth, we did not examine alcohol consumption in this study because face-to-face interviews have been shown to generate socially desirable answers to questions on this topic, with underreporting of alcohol consumption [73]. Lastly, due to data limitation, the measurement of social cohesion was limited to trust and safety indicators. More research is needed to develop an internationally accepted definition of social cohesion and means of operationalising this concept.

\section{Conclusions}

In this study, greater social cohesion was associated with adequate VF intake, active social participation, and not being a daily smoker among middle-aged and older adults in China. Higher educational levels and incomes were associated with favourable health behaviours, except that higher incomes were associated with insufficient PA. Our findings are an essential step toward a fuller understanding of the roles of social cohesion and SES in protecting healthy behaviours among older adults in China. Policymakers and health professionals designing health promotion strategies should aim to enhance social cohesion among middle-aged and older adults in China, which may vary between Chinese older men and women. 
Author Contributions: Conceptualization, Z.F., J.M.C., and A.P.N.; methodology, Z.F., J.M.C., and A.P.N.; software, Z.F. and J.M.C.; formal analysis, Z.F. and J.M.C.; writing-original draft preparation, Z.F.; writing-review and editing, Z.F., J.M.C., and A.P.N.; visualization, Z.F.; supervision, J.M.C. and A.P.N.; funding acquisition, Z.F. All authors have read and agreed to the published version of the manuscript.

Funding: ZF is supported by a China Scholarship Council fellowship (grant number: 201708310108; http:/ / www.csc.edu.cn/ accessed on 2 May 2021). This study used data from the World Health Organization's Study on Global AGEing and Adult Health, which is supported by the US National Institute on Aging through interagency agreements (OGHA 04034785, YA1323-08-CN-0020, and Y1-AG-1005-01) and a research grant (R01-AG034479). The funders had no role in the design of the study; in the collection, analyses, or interpretation of data; in the writing of the manuscript, or in the decision to publish the results.

Institutional Review Board Statement: Ethics approval was obtained from the ethics review committees of the World Health Organization and the Chinese Center for Disease Control and Prevention.

Informed Consent Statement: Informed consent was obtained from all study participants by the WHO SAGE research team who collected the data.

Data Availability Statement: The data presented in this study are openly available in WHO MultiCountry Studies Data Archive at: https://apps.who.int/healthinfo/systems/surveydata/index. $\mathrm{php} /$ catalog/13 (accessed on 2 May 2021).

Acknowledgments: We would like to express our appreciation to Yanfei Guo, a specialist at Shanghai Municipal Centre for Disease Control, for his valuable professional explanation of the construction of the China WHO SAGE data. We also thank all involved field workers, as well as to the respondents to WHO's Study on Global AGEing and Adult Health (SAGE) wave 1 in China. We are also grateful to the WHO for making the WHO SAGE dataset publicly available. We also appreciate Chunlin Jin, Shanlian Hu, Haiyin Wang, Hai Lin, Chunyan Xie, and Fen Li, for their continuous support for ZF.

Conflicts of Interest: The authors declare that there is no conflict of interest with respect to the research, authorship, and/or publication of this article.

\section{Appendix A}

Table A1. Social cohesion scale.

\begin{tabular}{|c|c|c|c|c|}
\hline \multicolumn{5}{|c|}{ How Much You Trust Different Groups of People... } \\
\hline To a very small extent & To a small extent & Neither great nor small extent & To a great extent & To a very great extent \\
\hline \multicolumn{5}{|c|}{ First, think about people in our neighbourhood. Generally speaking, would you say that you can trust them ... ? } \\
\hline 1 & 2 & 3 & 4 & 5 \\
\hline \multicolumn{5}{|c|}{ Now, think about people whom you work with. Generally speaking, would you say that you can trust them ... ? } \\
\hline 1 & 2 & 3 & 4 & 5 \\
\hline \multicolumn{5}{|c|}{ How about strangers? Generally speaking, would you say that you can trust them ... ? } \\
\hline 1 & 2 & 3 & 4 & 5 \\
\hline \multicolumn{5}{|c|}{ Questions about Safety in the Area Where You Live. } \\
\hline Not safe at all & Slightly safe & Moderately safe & Very safe & Completely safe \\
\hline \multicolumn{5}{|c|}{ In general, how safe from crime and violence do you feel when you are alone at home? } \\
\hline 1 & 2 & 3 & 4 & 5 \\
\hline \multicolumn{5}{|c|}{ How safe do you feel when walking down your street alone after dark? } \\
\hline 1 & 2 & 3 & 4 & 5 \\
\hline
\end{tabular}




\section{Appendix B}

Table A2. Social participation scale.

\begin{tabular}{l} 
How Often in the Last 12 Months Have You ... \\
\hline 1. Attended any public meeting in which there was a discussion of local or school affairs? \\
\hline 2. Met personally with someone you consider to be a community leader? \\
\hline 3. Attended any group, club, society, union or organisational meeting? \\
\hline 4. Worked with other people in your neighbourhood to fix or improve something? \\
\hline 5. Had friends over to your home? \\
\hline 6. Been in the home of someone who lives in a different neighbourhood than you do or had ... \\
them in your home? \\
\hline 7. Socialised with co-workers outside of work? \\
\hline 8. Attended religious services (not including weddings and funerals)? \\
9. Gotten out of the house/your dwelling to attend social meetings, activities, programmes or \\
events or to visit friends or relatives?
\end{tabular}

\section{Appendix C}

Table A3. Associations between social cohesion and socioeconomic status with health behaviours among males and females.

\begin{tabular}{|c|c|c|c|c|c|c|c|c|}
\hline & \multicolumn{2}{|c|}{ Sufficient PA } & \multicolumn{2}{|c|}{ Adequate VF Consumption } & \multicolumn{2}{|c|}{ Daily Smoker } & \multicolumn{2}{|c|}{ Social Participation $\S$} \\
\hline & $\begin{array}{c}\text { Males } \\
\text { OR }(95 \% \text { CI })\end{array}$ & $\begin{array}{c}\text { Females } \\
\text { OR }(95 \% \text { CI })\end{array}$ & $\begin{array}{c}\text { Males } \\
\text { OR }(95 \% \text { CI })\end{array}$ & $\begin{array}{c}\text { Females } \\
\text { OR }(95 \% \text { CI })\end{array}$ & $\begin{array}{c}\text { Males } \\
\text { OR }(95 \% \text { CI })\end{array}$ & $\begin{array}{c}\text { Females } \\
\text { OR }(95 \% \text { CI })\end{array}$ & $\begin{array}{l}\text { Males } \\
\text { B (SE) }\end{array}$ & $\begin{array}{c}\text { Females } \\
\text { B (SE) }\end{array}$ \\
\hline Social cohesion & $\begin{array}{c}1.178^{*} \\
(1.044-1.329)\end{array}$ & $\begin{array}{c}0.976 \\
(0.874-1.091)\end{array}$ & $\begin{array}{c}1.251^{* *} \\
(1.106-1.416)\end{array}$ & $\begin{array}{c}1.357^{* *} \\
(1.202-1.531)\end{array}$ & $\begin{array}{c}0.805^{* *} \\
(0.716-0.904)\end{array}$ & $\begin{array}{c}0.984 \\
(0.732-1.323)\end{array}$ & $\begin{array}{c}0.067 \\
(0.011)^{* *}\end{array}$ & $\begin{array}{c}0.080 \\
(0.010)^{* *}\end{array}$ \\
\hline Low education & $\begin{array}{c}0.941 \\
(0.826-1.073)\end{array}$ & $\begin{array}{c}1.184 \\
(1.034-1.356)\end{array}$ & $\begin{array}{c}0.866 \\
(0.759-0.989)\end{array}$ & $\begin{array}{c}0.723 \text { ** } \\
(0.620-0.841)\end{array}$ & $\begin{array}{c}1.320 * * \\
(1.163-1.498)\end{array}$ & $\begin{array}{c}1.413 \\
(0.938-2.129)\end{array}$ & $\begin{array}{c}-0.050 \\
(0.012)^{* *}\end{array}$ & $\begin{array}{c}-0.055 \\
(0.012)^{* *}\end{array}$ \\
\hline Income & $\begin{array}{c}0.595^{* *} \\
(0.519-0.682)\end{array}$ & $\begin{array}{c}0.616^{* *} \\
(0.541-0.700)\end{array}$ & $\begin{array}{c}2.506^{* *} \\
(2.175-2.887)\end{array}$ & $\begin{array}{c}2.806^{* *} \\
(2.430-3.240)\end{array}$ & $\begin{array}{c}0.807^{*} \\
(0.708-0.920)\end{array}$ & $\begin{array}{c}0.652 \\
(0.461-0.923)\end{array}$ & $\begin{array}{c}0.124 \\
(0.012)^{* *}\end{array}$ & $\begin{array}{c}0.081 \\
(0.011)^{* *}\end{array}$ \\
\hline Age & $\begin{array}{c}0.969 * * \\
(0.963-0.975)\end{array}$ & $\begin{array}{c}0.952 * * \\
(0.946-0.958)\end{array}$ & $\begin{array}{c}1.010 * \\
(1.003-1.017)\end{array}$ & $\begin{array}{c}0.990 * \\
(0.983-0.996)\end{array}$ & $\begin{array}{c}0.948 \text { ** } \\
(0.942-0.954)\end{array}$ & $\begin{array}{c}1.037^{* *} \\
(1.020-1.055)\end{array}$ & $\begin{array}{c}-0.004 \\
(0.001)^{* *}\end{array}$ & $\begin{array}{c}-0.006 \\
(0.001)^{* *}\end{array}$ \\
\hline Residence (rural) & $\begin{array}{c}0.840 \\
(0.736-0.960)\end{array}$ & $\begin{array}{c}0.568^{* *} \\
(0.501-0.644)\end{array}$ & $\begin{array}{c}0.493^{* *} \\
(0.432-0.563)\end{array}$ & $\begin{array}{c}0.426^{* *} \\
(0.373-0.486)\end{array}$ & $\begin{array}{c}1.704^{* *} \\
(1.503-1.933)\end{array}$ & $\begin{array}{c}1.076 \\
(0.778-1.488)\end{array}$ & $\begin{array}{c}0.152 \\
(0.012)^{* *}\end{array}$ & $\begin{array}{c}0.098 \\
(0.011)^{* *}\end{array}$ \\
\hline Non-Single & $\begin{array}{c}1.072 \\
(0.894-1.286)\end{array}$ & $\begin{array}{c}1.051 \\
(0.916-1.205)\end{array}$ & $\begin{array}{c}1.277 \\
(1.061-1.537)\end{array}$ & $\begin{array}{c}1.265^{*} \\
(1.092-1.466)\end{array}$ & $\begin{array}{c}0.878 \\
(0.708-0.920)\end{array}$ & $\begin{array}{c}0.951 \\
(0.677-1.338)\end{array}$ & $\begin{array}{c}0.035 \\
(0.017)\end{array}$ & $\begin{array}{l}-0.023 \\
(0.012)\end{array}$ \\
\hline Constant & $9.387^{* *}$ & $55.798^{* *}$ & 0.512 & $2.640 *$ & $41.854^{* *}$ & $0.002 * *$ & $\begin{array}{c}1.607 \\
(0.056) * *\end{array}$ & $\begin{array}{c}1.734 \\
(0.051)^{* *}\end{array}$ \\
\hline
\end{tabular}

${ }^{*} p<0.01{ }^{* *} p<0.001$. SE, standard error; OR, odds ratio; CI, confidence interval. ${ }^{\S}$ continuous variable. PA, physical activity; higher social participation scores indicate greater social participation.

\section{References}

1. Zhang, N.J.; Guo, M.; Zheng, X. China: A wakening giant developing solutions to population ageing. Gerontol. 2012, 52, 589-596. [CrossRef] [PubMed]

2. China-WHO Country Cooperation Strategy 2016-2020. Available online: http://www.wpro.who.int/china/160321_ccs_eng.pdf (accessed on 20 April 2019).

3. Prevention of Noncommunicable Diseases. Available online: https://www.who.int/ncds/prevention/introduction/en/ (accessed on 20 April 2019).

4. Nocon, M.; Keil, T.; Willich, S.N. Education, income, occupational status and health risk behaviour. J. Public Health 2007, 15, 401-405. [CrossRef]

5. Pampel, F.C.; Krueger, P.M.; Denney, J.T. Socioeconomic disparities in health behaviors. Annu. Rev. Sociol. 2010, 36, 349-370. [CrossRef] [PubMed]

6. $\quad$ Li, Y.C.; Jiang, B.; Zhang, M.; Huang, Z.J.; Qian, D.; Zhao, Z.P.; Wang, Y.F.; Zhou, M.G.; Wang, L.M. Vegetable and fruit consumption among Chinese adults and associated factors: A nationally representative study of 170,847 adults. Biomed. Environ. Sci. 2017, 30, 863-874. [CrossRef] [PubMed] 
7. Xu, F.; Yin, X.; Zhang, M.; Ware, R.S.; Leslie, E.; Owen, N. Cigarette smoking is negatively associated with family average income among urban and rural men in regional Mainland China. Int. J. Ment. Health Addict. 2007, 5, 17-23. [CrossRef]

8. Wu, F.; Guo, Y.; Chatterji, S.; Zheng, Y.; Naidoo, N.; Jiang, Y.; Biritwum, R.; Yawson, A.; Minicuci, N.; Salinas-Rodriguez, A. Common risk factors for chronic non-communicable diseases among older adults in China, Ghana, Mexico, India, Russia and South Africa: The study on global AGEing and adult health (SAGE) wave 1. BMC Public Health 2015, 15, 1-13. [CrossRef]

9. Lynch, J.L.; von Hippel, P.T. An education gradient in health, a health gradient in education, or a confounded gradient in both? Soc. Sci. Med. 2016, 154, 18-27. [CrossRef] [PubMed]

10. Du, S.; Mroz, T.A.; Zhai, F.; Popkin, B.M. Rapid income growth adversely affects diet quality in China-particularly for the poor! Soc. Sci. Med. 2014, 59, 1505-1515. [CrossRef]

11. Muntner, P.; Gu, D.; Wildman, R.P.; Chen, J.; Qan, W.; Whelton, P.K.; He, J. Prevalence of physical activity among Chinese adults: Results from the international collaborative study of cardiovascular disease in Asia. Am. J. Public Health 2005, 95, 1631-1636. [CrossRef]

12. Ng, S.W.; Howard, A.; Wang, H.; Su, C.; Zhang, B. The physical activity transition among adults in China: 1991-2011. Obes. Rev. 2014, 15, 27-36. [CrossRef]

13. Kohrman, M. Smoking among doctors: Governmentality, embodiment, and the diversion of blame in contemporary China. Med. Anthropol. 2008, 27, 9-42. [CrossRef]

14. Cradock, A.L.; Kawachi, I.; Colditz, G.A.; Gortmaker, S.L.; Buka, S.L. Neighborhood social cohesion and youth participation in physical activity in Chicago. Soc. Sci. Med. 2009, 68, 427-435. [CrossRef] [PubMed]

15. Fisher, K.J.; Li, F.; Michael, Y.; Cleveland, M. Neighborhood-level influences on physical activity among older adults: A multilevel analysis. J. Ageing Phys. Act. 2004, 12, 45-63. [CrossRef]

16. King, D. Neighborhood and individual factors in activity in older adults: Results from the Neighborhood and Senior Health Study. J. Ageing Phys. Act. 2008, 16, 144-170. [CrossRef] [PubMed]

17. Ueshima, K.; Fujiwara, T.; Takao, S.; Suzuki, E.; Iwase, T.; Doi, H.; Kawachi, I. Does social capital promote physical activity? A population-based study in Japan. PLoS ONE 2010, 5, e12135. [CrossRef] [PubMed]

18. Van Dyck, D.; Teychenne, M.; McNaughton, S.A.; De Bourdeaudhuij, I.; Salmon, J. Relationship of the perceived social and physical environment with mental health-related quality of life in middle-aged and older adults: Mediating effects of physical activity. PLoS ONE 2015, 10, e0120475. [CrossRef] [PubMed]

19. Yip, C.; Sarma, S.; Wilk, P. The association between social cohesion and physical activity in Canada: A multilevel analysis. Ssm-Popul. Health 2016, 2, 718-723. [CrossRef]

20. Cohen, D.A.; Finch, B.K.; Bower, A.; Sastry, N. Collective efficacy and obesity: The potential influence of social factors on health Soc. Sci. Med. 2006, 62, 769-778. [CrossRef] [PubMed]

21. Gao, J.; Fu, H.; Li, J.; Jia, Y. Association between social and built environments and leisure-time physical activity among Chinese older adults: A multilevel analysis. Bmc Pub. Health 2015, 15, 1317. [CrossRef]

22. Sampson, R.J. Local friendship ties and community attachment in mass society: A multilevel systemic model. Am. Soc. Rev. 1988, 53, 766-779. [CrossRef]

23. Cuevas, A.G.; Kawachi, I.; Ortiz, K.; Pena, M.; Reitzel, L.R.; McNeill, L.H. Greater social cohesion is associated with lower body mass index among African American adults. Prev. Med. Rep. 2020, 18, 101098. [CrossRef] [PubMed]

24. Franko, D.L.; Thompson, D.; Bauserman, R.; Affenito, S.G.; Striegel-Moore, R.H. What's love got to do with it? Family cohesion and healthy eating behaviors in adolescent girls. Int. J. Eat. Disord. 2008, 41, 360-367. [CrossRef] [PubMed]

25. Havemann, K.; Pridmore, P. Social cohesion: The missing link to better health and nutrition in a globalized world. In Proceedings of the World Bank Conference, "New Frontiers of Social Policy: Development in a Globalizing World", Arusha, Tanzania, 12-15 December 2005.

26. Mackenbach, J.D.; Lakerveld, J.; van Lenthe, F.J.; Kawachi, I.; McKee, M.; Rutter, H. Neighbourhood social capital: Measurement issues and associations with health outcomes. Obes. Rev. 2016, 17, 96-107. [CrossRef]

27. Alcalá, H.E.; Sharif, M.Z.; Albert, S.L. Social cohesion and the smoking behaviors of adults living with children. Addict. Behav. 2016, 53, 201-205. [CrossRef]

28. Fleischer, N.L.; Lozano, P.; Santillán, E.A.; Shigematsu, L.M.R.; Thrasher, J.F. The impact of neighbourhood violence and social cohesion on smoking behaviors among a cohort of smokers in Mexico. J. Epidemiol. Commun. Health 2015, 69, 1083-1090. [CrossRef] [PubMed]

29. Patterson, J.M.; Eberly, L.E.; Ding, Y.; Hargreaves, M. Associations of smoking prevalence with individual and area level social cohesion. J. Epidemiol. Commun. Health 2004, 58, 692-697. [CrossRef]

30. Andrews, J.O.; Mueller, M.; Newman, S.D.; Magwood, G.; Ahluwalia, J.S.; White, K.; Tingen, M.S. The association of individual and neighborhood social cohesion, stressors, and crime on smoking status among African-American women in southeastern US subsidized housing neighborhoods. J. Urban Health Bull. N. Y. Acad. Med. 2014, 91, 1158-1174. [CrossRef] [PubMed]

31. Feng, Z.; Cramm, J.M.; Nieboer, A.P. Social participation is an important health behaviour for health and quality of life among chronically ill older Chinese people. Bmc Geriatr. 2020, 20, 299. [CrossRef]

32. Social Participation and Social Cohesion in the EU Macro-Regions: Cultural Routes and Community Engagement. Available online: https://rm.coe.int/routes4u-elearning-manual-cultural-routes-and-community-engagement/16809ee $4 \mathrm{dd} \% 0 \mathrm{~A} \% 0 \mathrm{~A}$ (accessed on 25 August 2020). 
33. Latham, K.; Clarke, P.J. Neighborhood disorder, perceived social cohesion, and social participation among older Americans: Findings from the National Health \& Aging Trends Study. J. Aging Health 2016, 30, 3-26. [CrossRef]

34. Harell, A.; Stolle, D. Reconciling Diversity and Community? Defining Social Cohesion in Democracies. Social Capital and Social Cohesion: Interdisciplinary Theoretical Perspectives. In Contemporary Theoretical Perspectives on the Study of Social Cohesion andSocial Capita; Marc, H., Ed.; Royal Flemish Academy of Belgium for Science and the Arts: Brussels, Belgium, 2010.

35. Rajulton, F.; Ravanera, Z.R.; Beaujot, R. Measuring social cohesion: An experiment using the Canadian national survey of giving, volunteering, and participating. Soc. Indic. Res. 2007, 80, 461-492. [CrossRef]

36. Berkman, L.F. Social support, social networks, social cohesion and health. Soc. Work Health Care 2000, 31, 3-14. [CrossRef]

37. Durkheim, E. The division of labor in society (G. Simpson, Trans.); Free Press: New York, NY, USA, 1964.

38. Chan, J.; To, H.P.; Chan, E. Reconsidering social cohesion: Developing a definition and analytical framework for empirical research. Soc. Indic. Res. 2006, 75, 273-302. [CrossRef]

39. Social Cohesion Radar Measuring Common Ground: An International Comparison of Social Cohesion Methods Report. Available online: http:/ / aei.pitt.edu/id/eprint/74134 (accessed on 25 October 2020).

40. Larsen, C.A. Social Cohesion: Definition, Measurement and Developments. Available online: https://www-un-org.eur.idm.oclc. org/esa/socdev/egms/docs/2014/LarsenDevelopmentinsocialcohesion.pdf (accessed on 29 December 2020).

41. Gijsberts, M.; Van Der Meer, T.; Dagevos, J. 'Hunkering down'in multi-ethnic neighbourhoods? The effects of ethnic diversity on dimensions of social cohesion. Eur. Sociol. Rev. 2012, 28, 527-537. [CrossRef]

42. Van den Berg, M.M.; van Poppel, M.; van Kamp, I.; Ruijsbroek, A.; Triguero-Mas, M.; Gidlow, C.; Maas, J. Do physical activity, social cohesion, and loneliness mediate the association between time spent visiting green space and mental health? Environ. Behave. 2019, 51, 144-166. [CrossRef] [PubMed]

43. Han, J.; Zhao, Q.; Zhang, M. China's income inequality in the global context. Perspect. Sci. 2016, 7, 24-29. [CrossRef]

44. Fighting Income Inequality as a Means of Fostering Social Cohesion and Economic Development. (Report No. 14287). Available online: https: / / assembly.coe.int/nw/xml/XRef/Xref-XML2HTML-en.asp?fileid=23534\&lang=en (accessed on 16 April 2021).

45. Yang, T.; Barnett, R.; Jiang, S.; Yu, L.; Xian, H.; Ying, J.; Zheng, W. Gender balance and its impact on male and female smoking rates in Chinese cities. Soc. Sci. Med. 2016, 154, 9-17. [CrossRef] [PubMed]

46. Wu, F.; Yong, J.; Keqin, R.; Qian, J.; Li, X.; Ying, S. China: Study on Global AGEing and Adult Health (SAGE) Wave 1 National Report. Available online: https:/ / doi.org/10.13140/RG.2.1.1507.7287 (accessed on 20 October 2020).

47. Kowal, P.; Chatterji, S.; Naidoo, N.; Biritwum, R.; Fan, W.; Ridaura, R.L.; Maximova, T.; Arokiasamy, P.; Phaswana-Mafuya, N.; Williams, S.; et al. Data resource profile: The World Health Organization Study on global AGEing and adult health (SAGE). Int. J. Epidemiol. 2012, 41, 1639-1649. [CrossRef]

48. Xu, H.; Vorderstrasse, A.A.; Dupre, M.E.; McConnell, E.S.; Østbye, T.; Wu, B. Gender differences in the association between migration and cognitive function among older adults in China and India. Arch. Gerontol. Geriatr. 2019, 81, 31-38. [CrossRef]

49. McMullin, J.A.; Cairney, J. Self-esteem and the intersection of age, class, and gender. J. Ageing Stud. 2004, 18, 75-90. [CrossRef]

50. Ferguson, B.D.; Tandon, A.; Gakidou, E.; Murray, C.J. Estimating permanent income using indicator variables. In Health Systems Performance Assessment: Debates, Methods and Empiricism; World Health Organization: Geneva, Switzerland, 2003 ; pp. 747-760.

51. World Health Organization. Global strategy on Diet, Physical Activity and Health. Available online: https://www.who.int/ dietphysicalactivity/strategy/eb11344/strategy_english_web.pdf (accessed on 26 June 2019).

52. O'Brien, R.M. A caution regarding rules of thumb for variance inflation factors. Qual. Quant. 2007, 41, 673-690. [CrossRef]

53. Allik, J.; Realo, A. Individualism-collectivism and social capital. J. Cross-Cult. Psychol. 2004, 35, 29-49. [CrossRef]

54. Legh-Jones, H.; Moore, S. Network social capital, social participation, and physical inactivity in an urban adult population. Soc. Sci.Med. 2012, 74, 1362-1367. [CrossRef]

55. Lindström, M. Social capital, desire to increase physical activity and leisure-time physical activity: A population-based study. Public Health 2011, 125, 442-447. [CrossRef]

56. Machida, D.; Yoshida, T. Factors that Affect Nonmarket Fruit and Vegetable Receptions: Analyses of Two Cross-Sectional Surveys in Gunma, Japan. Agriculture 2019, 9, 230. [CrossRef]

57. Barnidge, E.K.; Hipp, P.R.; Estlund, A.; Duggan, K.; Barnhart, K.J.; Brownson, R.C. Association between community garden participation and fruit and vegetable consumption in rural Missouri. Int. J. Behav. Nutr. Phys. Act. 2013, 10, 128. [CrossRef] [PubMed]

58. Winters, M.; Barnes, R.; Venners, S.; Ste-Marie, N.; McKay, H.; Sims-Gould, J.; Ashe, M.C. Older adults' outdoor walking and the built environment: Does income matter? BMC Public Health 2015, 15, 876. [CrossRef]

59. Zhang, M.; Liu, S.; Yang, L.; Jiang, Y.; Huang, Z.; Zhao, Z.; Deng, Q.; Li, Y.; Zhou, M.; Wang, L.; et al. Prevalence of smoking and knowledge about the smoking hazards among 170,000 Chinese adults: A nationally representative survey in 2013-2014. Nicotine Tob. Res. 2019, 21, 12. [CrossRef] [PubMed]

60. Liu, S.; Zhang, M.; Yang, L.; Li, Y.; Wang, L.; Huang, Z.; Wang, L.; Chen, Z.; Zhou, M. Prevalence and patterns of tobacco smoking among Chinese adult men and women: Findings of the 2010 national smoking survey. J. Epidemiol. Commun. Health 2017, 71, 154-161. [CrossRef] [PubMed]

61. Qian, J.; Cai, M.; Gao, J.; Tang, S.; Xu, L.; Critchley, J.A. Trends in smoking and quitting in China from 1993 to 2003 : National health service survey data. Bull. W. H. O. 2010, 88, 769-776. [CrossRef] 
62. Gang, H.; Pekkarinen, H.; Hänninen, O.; Yu, Z.; Huiguang, T.; Zeyu, G.; Nissinen, A. Physical activity during leisure and commuting in Tianjin, China. Bull. W. H. O. 2002, 80, 933-938.

63. Park, B.; Park, J.; Jun, J.K.; Choi, K.S.; Suh, M. Gender differences in the association of smoking and drinking with the development of cognitive impairment. Plos One 2013, 8, e75095. [CrossRef] [PubMed]

64. Selivanova, A.; Cramm, J.M. The relationship between healthy behaviors and health outcomes among older adults in Russia. Bmc Public Health 2014, 14, 1-13. [CrossRef] [PubMed]

65. Giovino, G.A.; Mirza, S.A.; Samet, J.M.; Gupta, P.C.; Jarvis, M.J.; Bhala, N.; Peto, R.; Zatonski, W.; Hsia, J.; Morton, J.; et al. Tobacco use in 3 billion individuals from 16 countries: An analysis of nationally representative cross-sectional household surveys. Lancet 2012, 380, 668-679. [CrossRef]

66. Ma, G.X.; Shive, S.E.; Ma, X.S.; Toubbeh, J.I.; Tan, Y.; Lan, Y.J.; Zhai, C.K.; Pei, X. Social influences on cigarette smoking among mainland Chinese and Chinese Americans: A comparative study. Am. J. Health Stud. 2013, 28, 12-20.

67. Kan, M.Y.; He, G. Resource bargaining and gender display in housework and care work in modern China. Chin. Sociol. Rev. 2018, 50, 188-230. [CrossRef]

68. Hong, S.A.; Kim, K.; Kim, M.K. Educational attainment and differences in fruit and vegetable consumption among middle-aged adults in the Korean National Health and Nutrition Examination Survey IV. Nutr. Res. Pract. 2012, 6, 263. [CrossRef]

69. Vest, J.; Valadez, A. Perceptions of neighborhood characteristics and leisure-time physical inactivity-Austin/Travis County, Texas, 2004. Morb. Mortal. Wkly. Rep. 2005, 54, 926-928.

70. Sun, V.K.; Cenzer, I.S.; Kao, H.; Ahalt, C.; Williams, B.A. How safe is your neighborhood? Perceived neighborhood safety and functional decline in older adults. J. Gen. Intern. Med. 2012, 27, 541-547. [CrossRef]

71. Social Cohesion and Development: Using Cross-Country Data to Understand Cohesive Societies. Available online: http: / / citeseerx.ist.psu.edu/viewdoc/download?doi=10.1.1.230.4448\&rep=rep1\&type=pdf (accessed on 23 December 2020).

72. Spring, B.; Moller, A.C.; Coons, M.J. Multiple health behaviors: Overview and implications. J. Public Health 2012, 34, 3-10. [CrossRef] [PubMed]

73. Midanik, L.T.; Greenfield, T.K.; Rogers, J.D. Reports of alcohol-related harm: Telephone versus face-to-face interviews. J. Stud. Alcohol. 2001, 62, 74-78. [CrossRef] [PubMed] 